\title{
Editorial Note: Outlook of the Review of Socionetwork Strategies in 2018
}

\author{
Yasuharu Ukai ${ }^{1}$ \\ Published online: 7 November 2018 \\ (c) Springer Japan KK, part of Springer Nature 2018
}

\section{Introduction}

The editorial board of the Review of Socionetwork Strategies received seventeen papers from 31 October 2017 to 26 October 2018. Eleven papers were accepted as articles, and one as a research note. Two were withdrawn. Four are on the process of reviewing by two anonymous referees.

I would like to review the situation of the Review of Socionetwork Strategies, RSOC, as Honorary Chief Editor of this journal.

\section{Time Series of RSOC}

The time series data of articles and notes from RSOC are described in Fig. 1. The rate of acceptance was $70 \%$ in 2018 . The editorial board continually receives submissions related to computer science and social science from all over the world.

The submitted manuscripts were peer-reviewed by two anonymous referees. The editors at RSOC decided to accept, reject, or conditionally accept based on the reports from the referees. Average review period is about 22 weeks. The longest reviewing time was 44 weeks, but this was an extraordinary case. The shortest reviewing time was 8 weeks in 2018 .

Authors were requested to revise their manuscript according to the referees' comments, suggestions, and questions. In certain cases, the editorial board promoted a manuscript to an Article or demoted it to a Research Note. For Volume 12 in 2018, this did not happen. $100 \%$ of the accepted manuscripts for Volume 12 were accepted conditionally. In 2018, the authors were supposed to return the revised manuscript with answers to the referees' remarks within 2-4 weeks. This deadline was very difficult for the authors, but all of them succeeded within this requirement.

Yasuharu Ukai

v751832@kansai-u.ac.jp

1 Research Institute for Socionetwork Strategies, Kansai University, Suita, Osaka 564-8680, Japan 


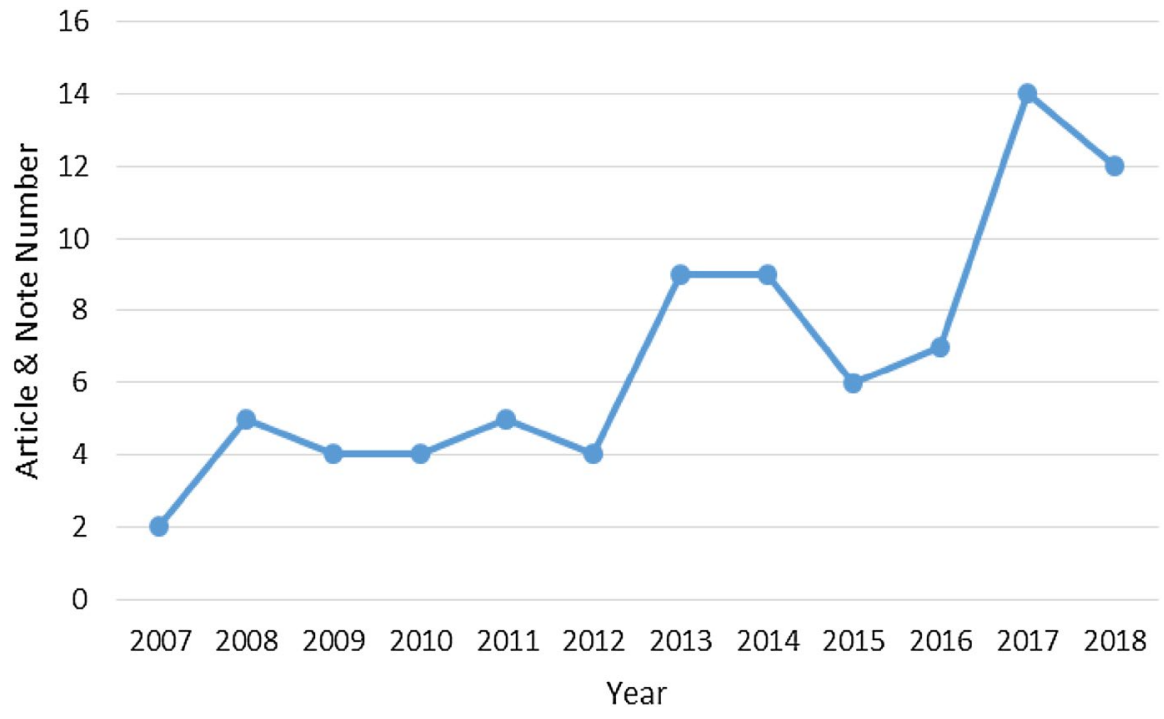

Fig. 1 Time series of RSOC articles and notes (Except Editorial Notes and Newsletters)

The affiliated institutes of the authors are located in Japan, Greece, India, Thailand, and Algeria.

\section{Full Text Article Requested}

In Fig. 2, the number of full article requests through the Internet between January 2014 and December 2017 is shown monthly. Obviously, the academic calendars of universities effect the downloading of article requests. January and December show the most downloads for PDF file article requests from scholars and graduate students all over the world.

In Fig. 3, the number of full article requests through the Internet between 2010 and 2017 is also shown annually.

\section{Geographical Distribution of Downloads}

In Fig. 4, the geographical distribution of downloading article requests is reported. The editorial board is located in Osaka, Japan. 78.6\% of the members of the editorial board are professors affiliated with universities in Japan. Therefore, it is reasonable that almost all article requests were from the Asia-Pacific area in 2009. However, 


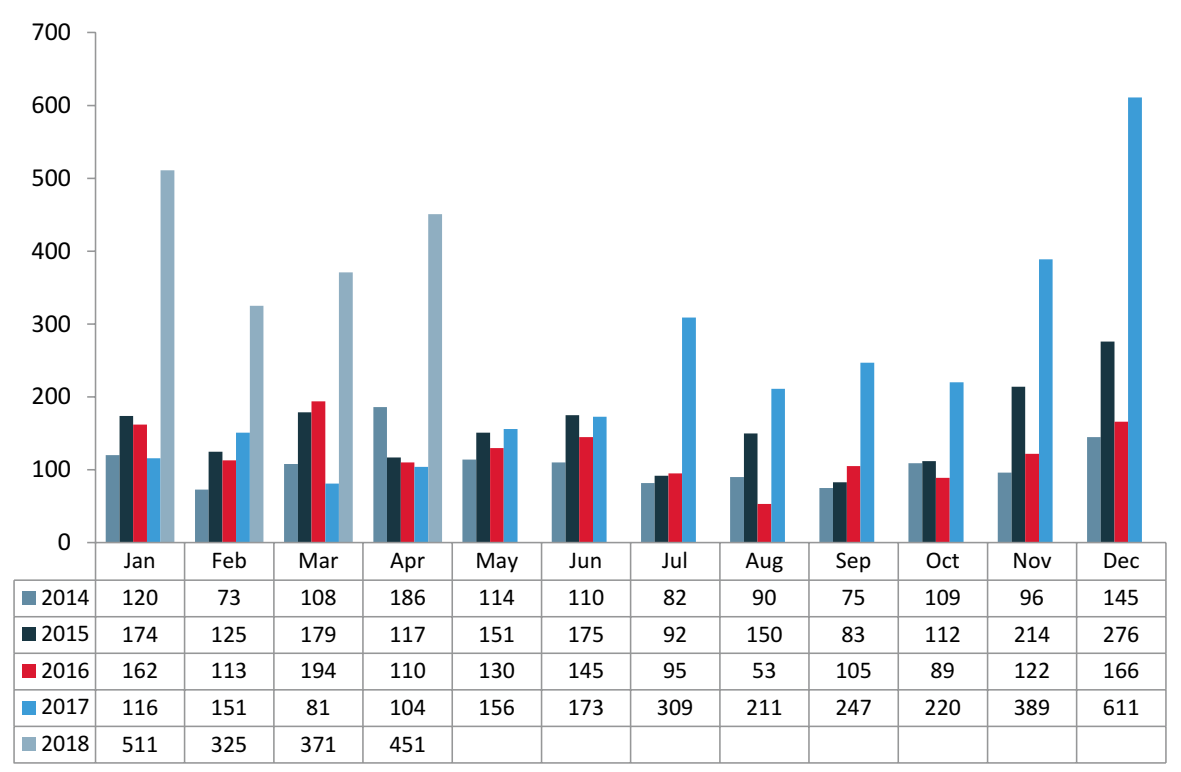

Fig. 2 Full-text article requests Jan 2014-Apr 2018

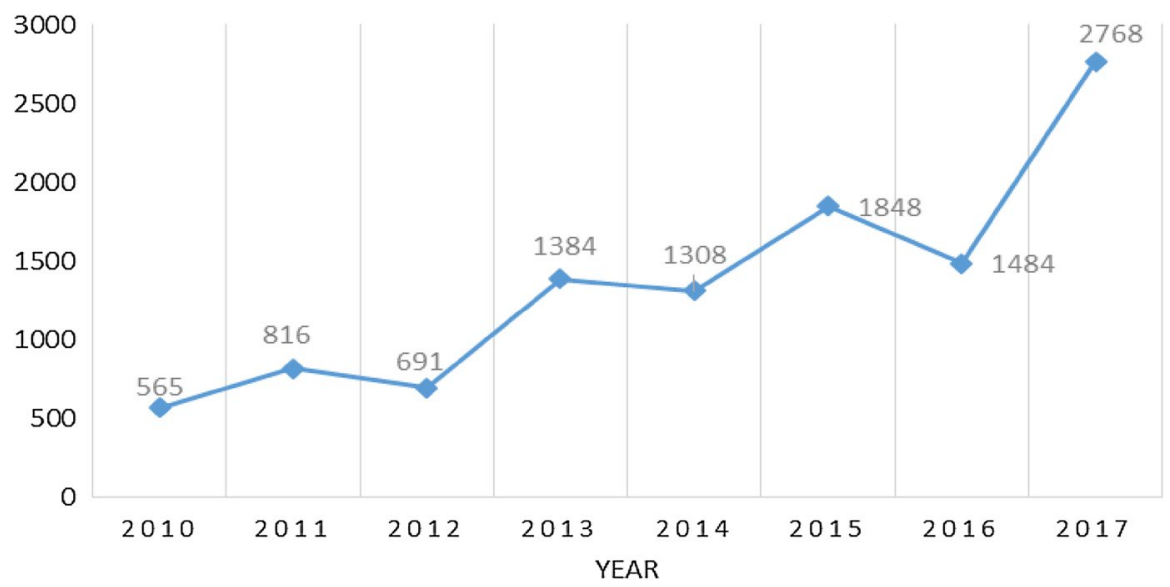

Fig. 3 Time series of RSOC full-text article requests

in 2017, the requests from North America and Europe have increased to 37\% from $20 \%$ in 2012.

The editorial board is satisfied with the increasing area variety of full text article requests, especially from Europe, North America and Middle East. 


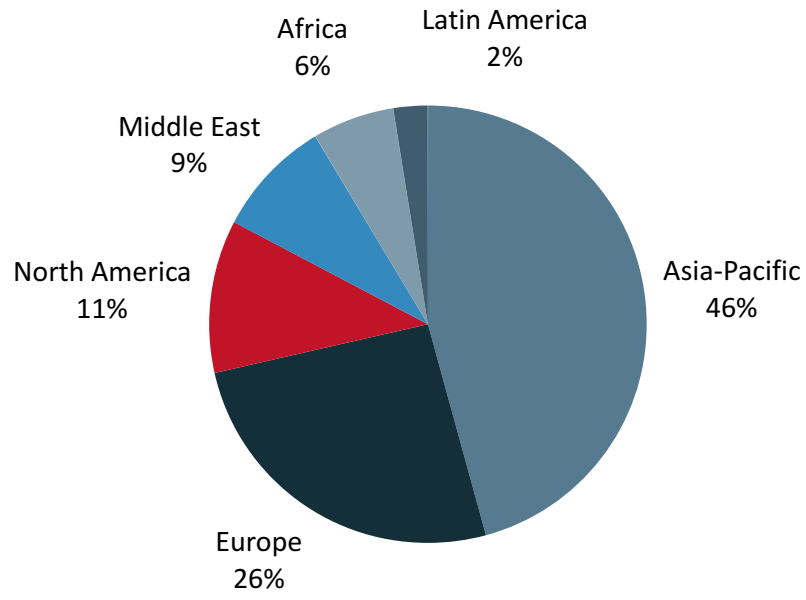

Fig. 4 Full text article requests by geography: 2017

\section{Rank of Articles Cited and Downloaded}

The ranking of article citations between 2007 and 2016 is described in Table 1. The top articles are by Tsumoto and Tsumoto [1,2] about medical statistics. The third most cited article is by Jorgenson and $\mathrm{Vu}$ [3] about econometrics. The fourth article is by Yada et al. [4] regarding management science. The fifth most cited article is by Takizawa et al. [5] of computer science. The sixth article is by Ukai and Takemura [6] about econometrics and computer science. The seventh article is Lin and Hong [7] regarding management science.

The variety of the academic fields has been amazing. However, all the articles are related to computer science nowadays.

The ranking of full text article downloading in 2017 is summarized in Table 2. It is very interesting to the editorial board to see the difference between the citation and the downloading. We are waiting for the submission of the statistical research concerning this time, the discrepancy.

\section{Editorial Board}

The Review of Socionetwork Strategies, RISS, Kansai University, Suita, Osaka, 564-8680, Japan 


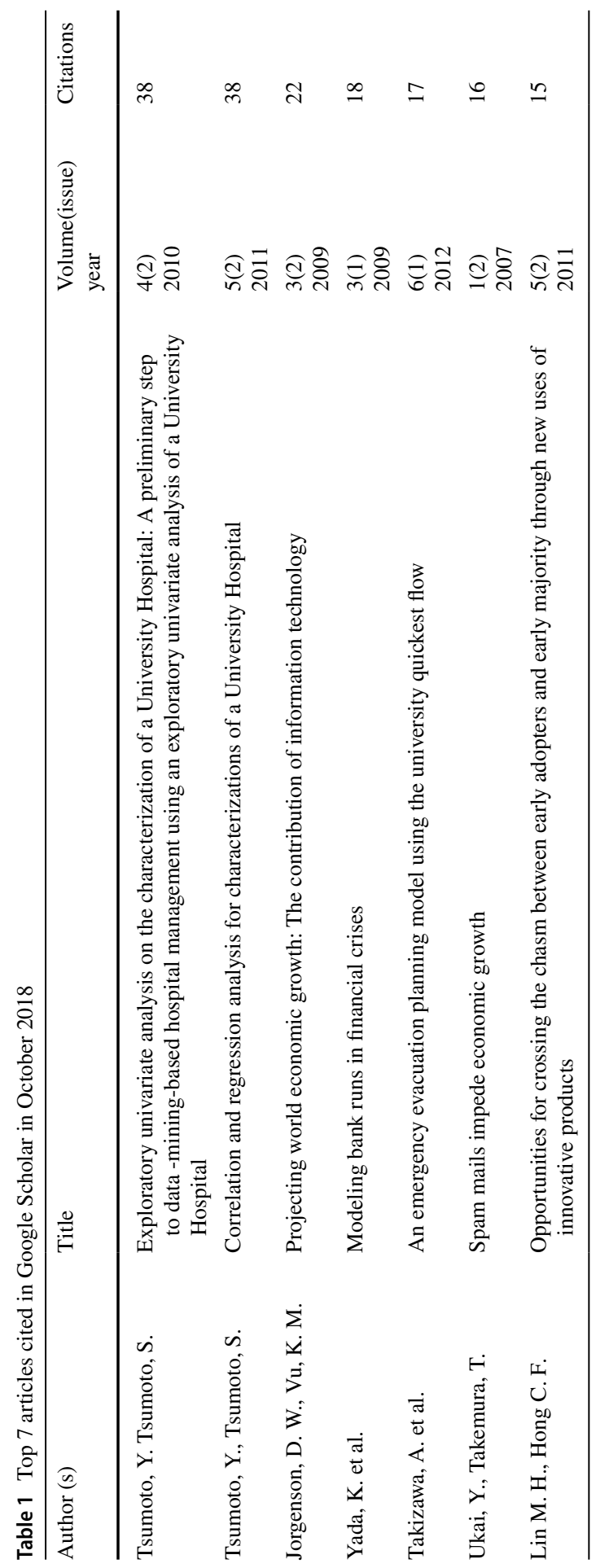




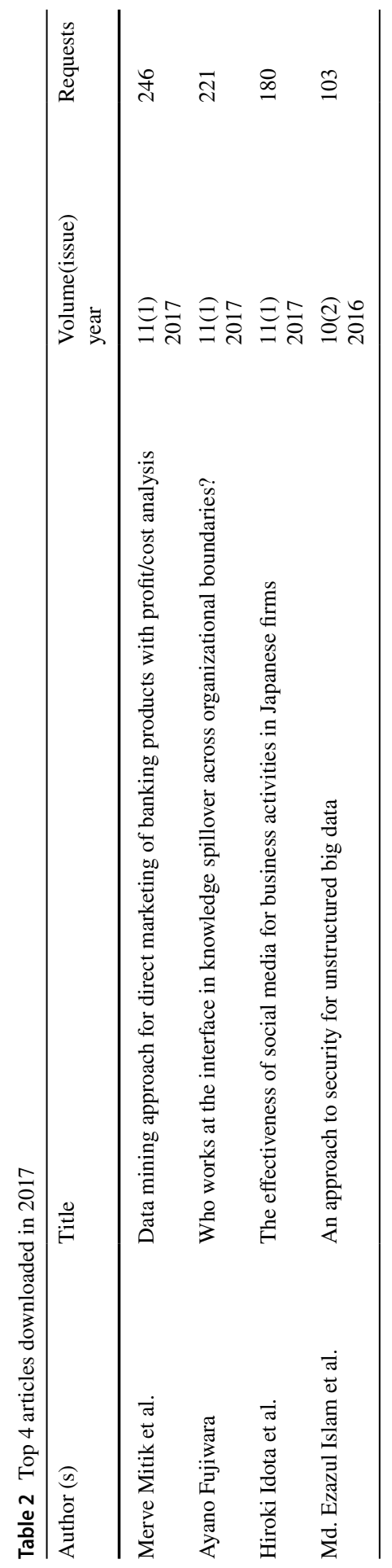


Acknowledgements The author wishes to thank the technical help by Mr. Yutaka Hirachi at Springer Japan KK.

\section{References}

1. Tsumoto, Y., \& Tsumoto, S. (2010). Exploratory univariate analysis on the characterization of a University Hospital: A preliminary step to data-mining-based hospital management using an exploratory univariate analysis of a University Hospital. The Review of Socionetwork Strategies., 4(2), 47-63.

2. Tsumoto, Y., \& Tsumoto, S. (2011). Correlation and regression analysis for characterizations of a University Hospital. The Review of Socionetwork Strategies., 5(2), 43-55.

3. Jorgenson, D. W., \& Vu, K. M. (2009). Projecting world economic growth: The contribution of information technology. The Review of Socionetwork Strategies., 3(2), 35-49.

4. Yada, K., Washio, T., Ukai, Y., \& Nagaoka, H. (2009). Modeling bank runs in financial crises. The Review of Socionetwork Strategies., 3(1), 19-31.

5. Takizawa, A., Inoue, M., \& Katoh, N. (2012). An emergency evacuation planning model using the university quickest flow. The Review of Socionetwork Strategies., 6(1), 15-28.

6. Ukai, Y., \& Takemura, T. (2007). Spam mails impede economic growth. The Review of Socionetwork Strategies., 1(2), 14-22.

7. Lin, M. H., \& Hong, C. F. (2011). Opportunities for crossing the chasm between early adopters and early majority through new uses of innovative products. The Review of Socionetwork Strategies., 5(2), 27-42. 